\title{
Feasibility Study of Bitcoin Hedging the U.S. Stock Market
}

\author{
Shiyun $\mathrm{He}^{1,{ }^{*}, \dagger}$, Yingjie Sheng ${ }^{2, *},{ }^{*}$, Ziyang Zang ${ }^{3, *}, \dagger$ \\ ${ }^{1}$ School of Business, Macau University of Science and Technology, Macau 519000, China \\ ${ }^{2}$ College of Finance and Statistics, Hunan University, Changsha 410000, China \\ ${ }^{3}$ James Madison College, Michigan State University, East Lansing 48823, the U.S. \\ *Corresponding author. Email: 1809853mb011022@student.must.edu.mo;syj20000312@163.com; \\ zangziy1@msu.edu \\ ${ }^{\dagger}$ These authors contributed equally.
}

\begin{abstract}
Hedge strategies are used with different terms to evaluate whether the co-movement between the U.S. stock market and Bitcoin can be used to optimize the portfolio. As for the representative stock indexes, we construct long-term and short-term hedge portfolios of the S\&P 500 and NASDAQ with Bitcoin based on the least variance hedging view. It turns out that long-term hedges are less effective than short-term hedges. To further test the correctness of the conclusion, in the context of the recently enacted and implemented double-reduction policy, we take the market value as the weight, select 5 stocks with large market value to build a portfolio, and hedge them with Bitcoin for a week. The conclusion was still in line with our expectations. By testing the feasibility of hedge between U.S. equity and Bitcoin, this research can provide investors with effective investment ideas and reveal the essence of hedge: the assets of the two hedges should have similar volatility.
\end{abstract}

Keywords: U.S. stock market, Bitcoin, Hedge, Feasibility.

\section{INTRODUCTION}

From the beginning of 2020: the world economy has been affected by Covid-19, not only to Underdeveloped countries but also developing and developed countries [1-3], the U.S stock market has experienced dramatic volatility [4], and the stock market has appeared to circuit breaker mechanism many times in a short period [5]. The U.S. stock market has experienced an incredible decline, which is the most serious decline since 2008. The pandemic has had a huge impact on both traditional and financial industries. People are eager to find products that can be invested in to keep their assets from depreciating.

Compared with traditional industries, the rapid growth of the emerging field of digital currency in 2020 has attracted people's attention. Starting in 2020, Bitcoin has attracted more and more attention in the world [6]. In 2020, the price of Bitcoin had doubled, and its market value has exceeded 500 billion, which has surpassed many well-known listed companies. Some analysts believe that the pandemic has impacted traditional currencies and assets, accelerating people's acceptance of digital currencies. The decline in traditional investment interest rates also contributed to the rise of Bitcoin [7]. More and more people are willing to try to invest in digital currency, and the characteristics of 2020 Bitcoin's rise are based on the weakening of traditional investment products. Can financial assets with high certainty hedge against the downturn in the traditional financial industry?

When exploring new hedging tools, people paid attention to the changes in Bitcoin and became interested in the hedging effect of Bitcoin. More and more people started Consider using Bitcoin as a hedging tool to deal with the turbulent stock market [8]. This idea has been debated in the financial community. Some people think that Bitcoin hedging is unreliable and cannot be used as a hedge against the U.S. stock market [9-11]. Some people think that Bitcoin is a relatively new financial asset, and there is no reason why it cannot be used as a hedging tool [12].

The purpose of our experiment is to test whether Bitcoin can be used as a hedging tool for the U.S. stock market. Whether Bitcoin has hedging ability with stock 
has a huge impact on the entire hedge fund industry that if it can hedge the stock market, it can be used as a useful new hedging tool instead of traditional hedge tools, such as gold, to decrease the risk of the U.S. stock market when the stock market fluctuates violently. People will have more choices when we encounter severe stock market volatility in the future. Better protect your assets.

When we select data, we think that the two indexes that best represent the U.S. stock market are S\&P500 [13] and NASDAQ, so we select these two data to reflect the changes in the U.S. stock market. Our experiment intercepted the S\&P 500 and NASDAQ index to hedge with the Bitcoin and compare the hedging effectiveness and return per unit risk before and after the hedge to show the hedging effect of Bitcoin in both the long and short term. We also set up a portfolio, which included five stocks influenced by the double-reduction policy to further testing the hedging ability of Bitcoin in the short-term and the impact of falling oil prices on the U.S. stock market after Russia and OPEC failed to reach an oil production reduction agreement in March 2021 [14]. Them we get the result that Bitcoin has a hedging effect in both long-term and short-term but may be more useful to hedge the stock market in the short-term.
Our research will show the data and methods of how we make the hedge ratio, hedge portfolio, and how we test the hedge performance first. After that, we will explain the result we get in both long-term and short-term, and finally conclude the hedge effect of Bitcoin. We use our experiment to finally determine whether Bitcoin can be used to hedge the U.S. stock market, and this is an exploration of a new hedging tool.

\section{DATA AND RESEARCH METHOD}

\subsection{Data}

For a long-term hedge, we collected 560 daily closing prices covering the period from January 23, 2020, to August 5, 2021, for Bitcoin, S\&P500, and NASDAQ.

The long term (Figure 1\&2) is from the first Covid-19 patient in the United States to the time of writing this article (August 6, 2021). During this period, considering that the U.S. stock market has been affected by Covid-19, we can try to explore the ability of the U.S. stock market to hedge with Bitcoin when it encounters risks. This is how we choose this time frame as the material for our experiment.

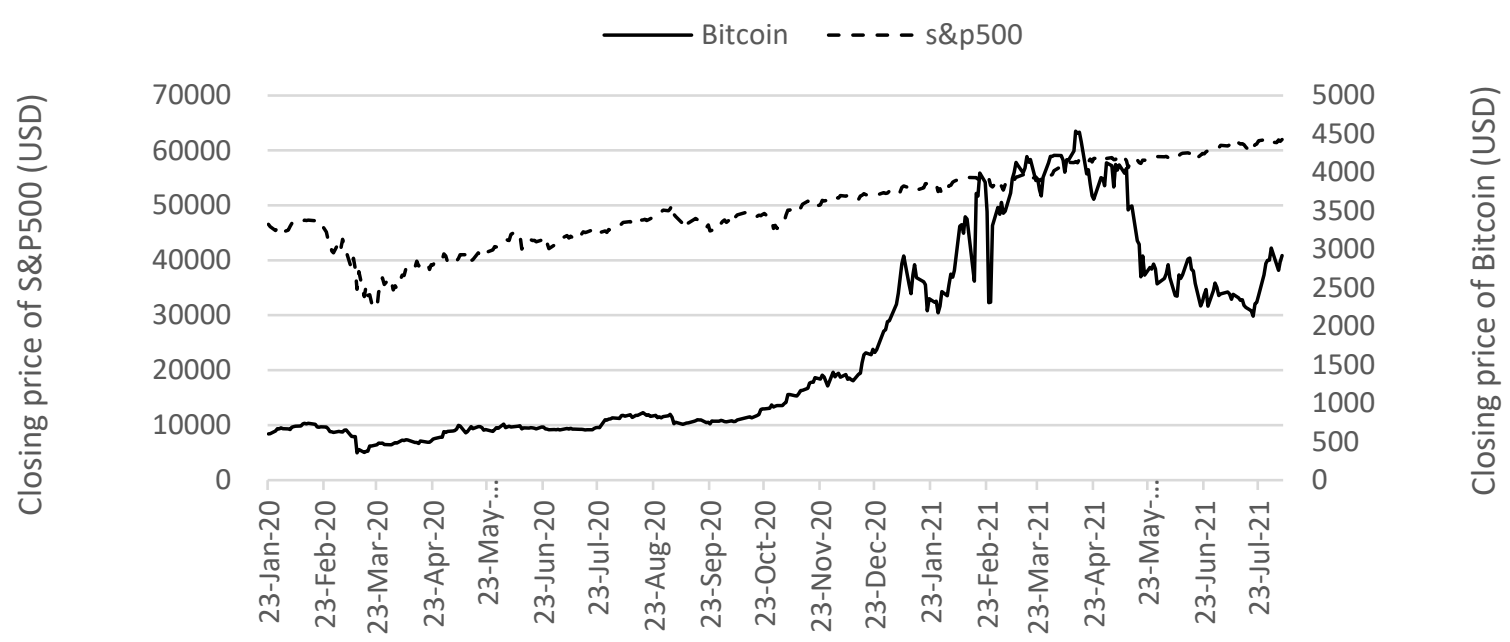

Figure 1. The closing price of S\&P500 and Bitcoin

For a short-term hedge, to explore the feasibility of hedge with Bitcoin in the context of the pandemic, we excerpted the data of Bitcoin, S\&P 500, and NASDAQ from March 2, 2020, to March 13, 2020. This time was affected by Covid-19 and Russia's failure to reach a production reduction agreement with OPEC. We also constructed a portfolio of five education stocks and held the hedge portfolio for one week from June 23, 2021, to June 31, 2021, to test the effect of bitcoin hedges under the double-reduction policy. The education stock list is provided in Table 2.

Prices for Bitcoin were obtained from https://coinmarketcap.com. The data of S\&P 500, NASDAQ, and five education stocks to build our portfolio were gathered from yahoo finance. (https://finance.yahoo.com/) 


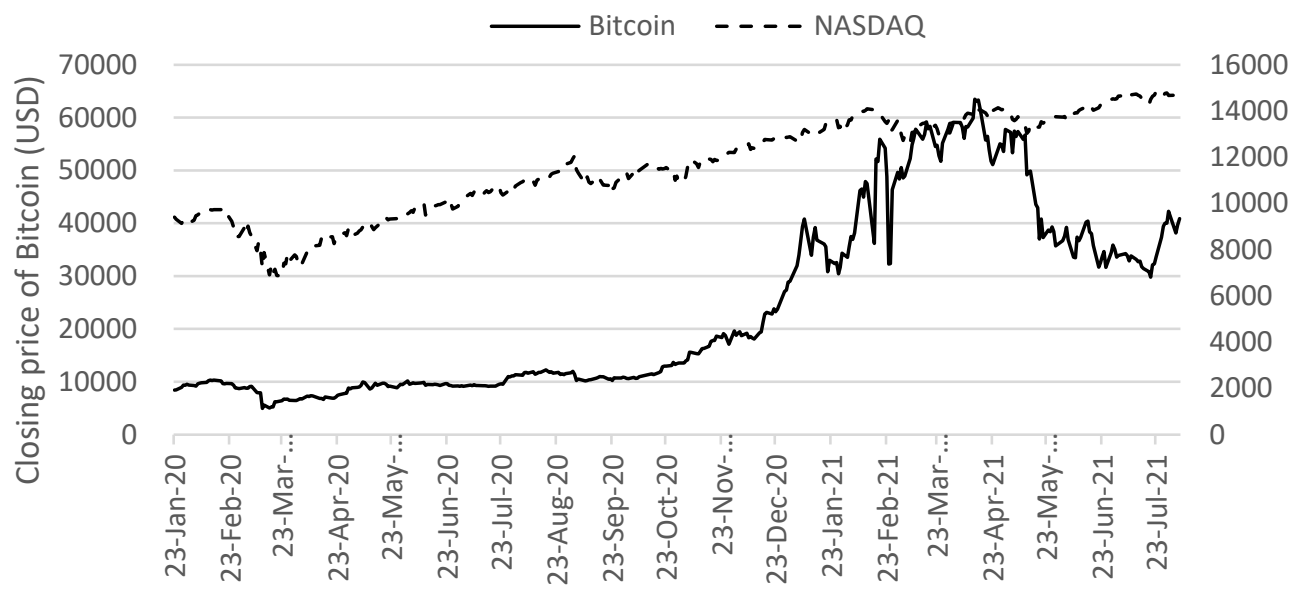

Figure 2. The closing price of NASDAQ and Bitcoin

\subsection{Methodology}

\subsubsection{Daily return}

Considering the distributed nature of asset prices and the stability of data, the definition of daily return used in our research is:

$$
R_{t}=\operatorname{Ln}\left(P_{t} / P_{t-1}\right) \times 100 \%
$$

where $P_{t}$ and $P_{t-1}$ are the prices of assets that day and the day before.

\subsubsection{Portfolio weights and portfolio return}

We considered a portfolio consisting of several stocks with large market capitalization under a certain type to examine whether Btcoin can be used in this specific area of the stock market. The weights of individual stocks $\left(W_{i}\right)$ and portfolio return $\left({ }^{R} p\right)$ are determined as follows:

$$
\begin{gathered}
W_{i}=\frac{M V_{i}}{\sum_{\mathrm{i}=1}^{n} M V_{i}} \\
R_{p t}=\sum_{i=1}^{n} W_{i} \times R_{i t}
\end{gathered}
$$

where $W_{i}, M V_{i}$ and $R_{i t}$ respectively represent the weight, market value and return rate at time $t$ of stock i. $\mathrm{n}$ is the number of stocks in the portfolio. Note that this portfolio, the S\&P 500, and the NASDAQ will be treated as hedged assets (unhedged portfolios).

\subsubsection{Hedge ratio}

Based on the assumption that all investors in the market are risk-averse, we believe that the primary purpose of a hedge is to minimize risks. In other words, the optimal hedge ratio should minimize the return variance of the whole hedge portfolio. Therefore, we adopt the hedge ratio $(h)$ proposed in John C. hull (1993) [15].

$$
h=\rho \frac{\sigma_{\mathrm{S}}}{\sigma_{\mathrm{b}}}
$$

where ${ }^{\rho}$ is the correlation coefficient between the change in return of the hedged asset and Bitcoin. $\sigma_{\mathrm{S}}$ and $\sigma_{b}$ are referred to as the standard deviation of the change in return on hedged assets and the change in return on Bitcoin, respectively.

\subsubsection{Performance evaluation}

We used hedge portfolio return $\left(R_{h t}\right)$, return per unit $\operatorname{risk}\left(R_{t}^{*}\right)$ and hedge effectiveness (HE) as key metrics for performance analysis.

Hedged portfolio return is the difference between the return rate of the hedged asset and the return rate of Bitcoin multiplied by the hedge ratio, as shown in Eq. (5)

$$
R_{h t}=R_{s t}-h \times R_{b t}
$$

where $R_{S t}$ is the return of the hedged assets, $R_{\mathrm{b} t}$ is the return for Bitcoinh, and represents the hedge ratio.

Return per unit $\operatorname{risk}\left(R_{j}^{*}\right)$ is the indicator that 
facilitates us to comprehensively examine the performance of a hedge portfolio from the perspectives of risk and return.

$$
R_{j}^{*}=\frac{R_{j t}}{\sigma_{j t}}, j=\left\{\begin{array}{lc}
s, & \text { unhedged } p \text { ortfolio } \\
h, & \text { hedge port folio }
\end{array}\right.
$$

where $R_{j t}, \sigma_{j t}$ are the value and standard deviation of the portfolio $\mathrm{j}$.

Refer to the basic method of evaluating the hedge effectiveness proposed by Ederington(1979) [16]. HE is defined in Eq. (7):

$$
H E=\frac{\operatorname{Var}\left(R_{S}\right)-\operatorname{Var}\left(R_{h}\right)}{\operatorname{Var}\left(R_{S}\right)} \times 100 \%
$$

where $\operatorname{Var}\left(R_{\mathrm{S}}\right)$ is the variance of unhedged portfolio rate, $\operatorname{Va}\left(R_{h}\right)$ is the variance of hedge portfolio return.

\section{EMPIRICAL RESULTS}

\subsection{Long-term hedge}

For the long term, we adopt the S\&P 500 and the NASDAQ, two stock indexes that represent the U.S. stock market. We use these two indexes separately to build the hedge portfolio with Bitcoin to see the hedge effect of the Bitcoin after the COVID-19 from January 23, 2020, to August 5, 2021. We used the return per unit risk, shown in Figures 3 and 4, and hedge effectiveness (HE) shown in Table 1 to test the hedge performance of the Bitcoin.

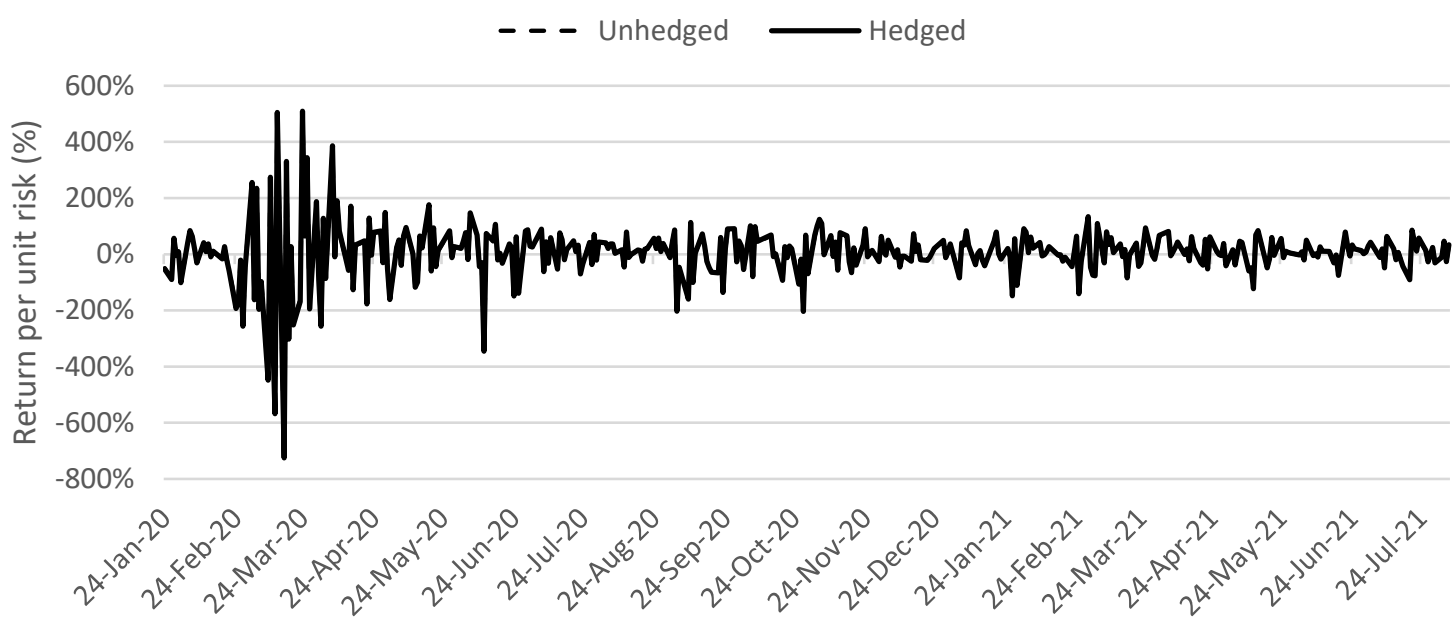

Figure 3. Hedge the S\&P 500 with Bitcoin

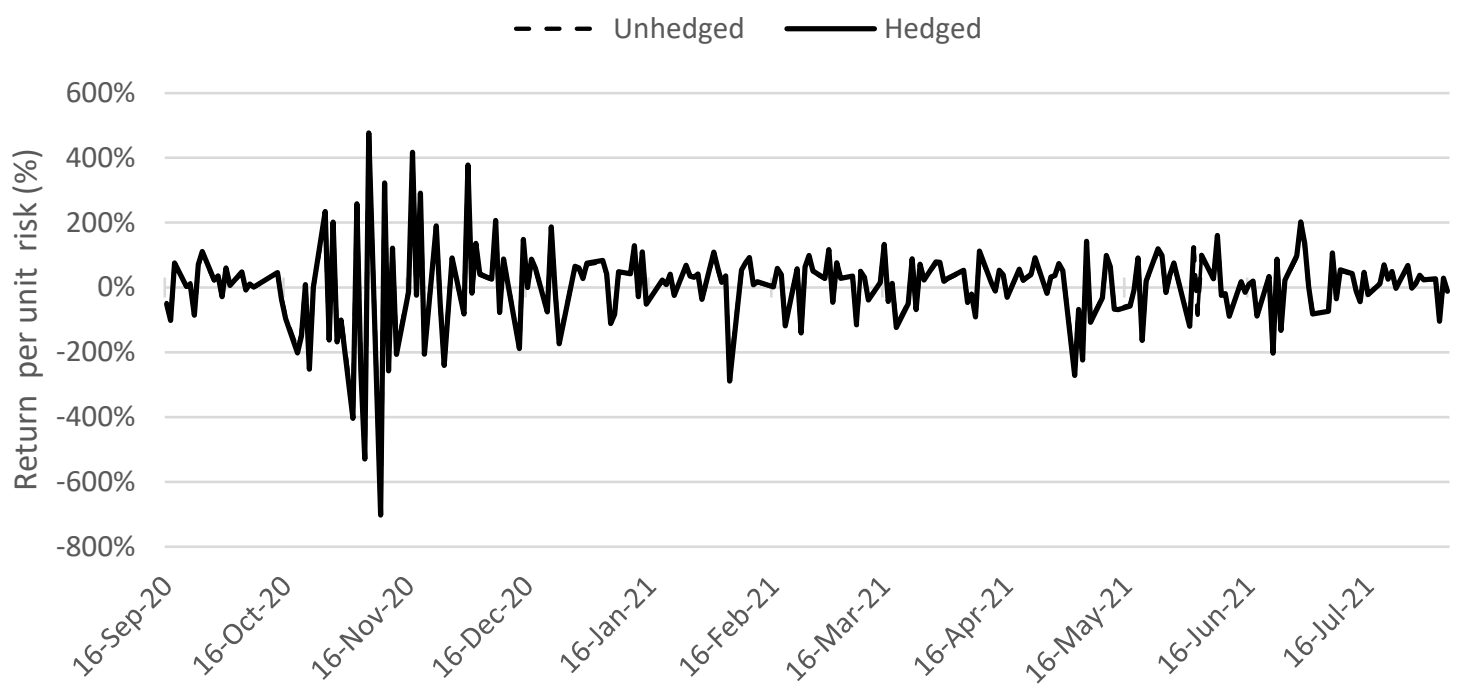

Figure 4. Hedge the NASDAQ with Bitcoin 
Table 1. Hedge ratio (h) and hedge effectiveness (HE) of Long-Term hedge portfolios

\begin{tabular}{ccc}
\hline Hedge Portfolios & $\mathrm{h}$ & $\mathrm{HE}$ \\
\hline S\&P 500 vs. Bitcoin & 0.0823 & $8.00 \%$ \\
NASDAQ vs. Bitcoin & 0.0957 & $9.43 \%$ \\
\hline
\end{tabular}

Notes: This table reports the hedge ratio (h) of long-term hedged assets and Bitcoin hedging transactions and each sample period's hedge effectiveness (HE).

In Figure 3 and Figure 4, we can find that the return per unit risk of Bitcoin with the S\&P 500 and the NASDAQ has nearly no change before and after the hedge. But from Table 1, the hedge effectiveness (HE) of S\&P 500 with Bitcoin is $8.00 \%$, and the hedge effectiveness (HE) of NASDAQ with Bitcoin is $9.43 \%$.

From this, we can conclude that bitcoin can be used as a hedge against U.S. stocks in the long run. According to the return per unit risk, although the hedge may not influence the return, Bitcoin can eliminate $8 \%$ of the risk of the S\&P 500 and $9.43 \%$ of the risk of NASDAQ. This means it still has the function to reduce the risk but is not that effective.

\subsection{Short-term hedge}

In the short term, we did two tests to see the hedge effect of Bitcoin. In the first test, we choose the short period during the COVID-19 from March 2, 2020, to March 13, 2020, and use Bitcoin to hedge with the S\&P 500 and the NASDAQ. Since China's recent double reduction policy has impacted U.S.-listed Chinese education stock, in this test, we constructed a representative portfolio to hedge with Bitcoin from June 26, 2021, to June 31, 2021, after the policy announcement. The hedge performance is shown below:

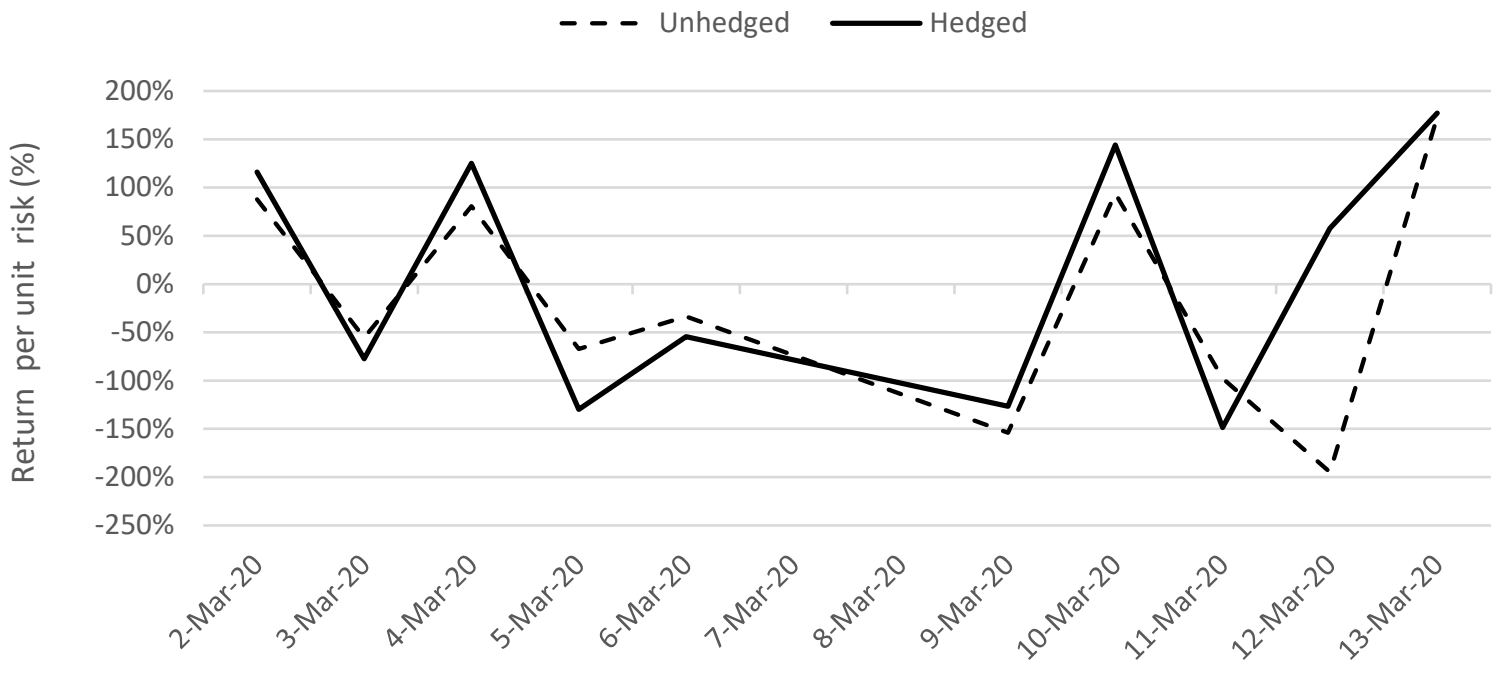

Figure 5. Return per unit risk (the S\&P 500 with Bitcoin)

Notes: This figure shows the return per unit risk of the S\&P 500 with Bitcoin before and after hedging to illustrate the performance of hedging by Bitcoin. 


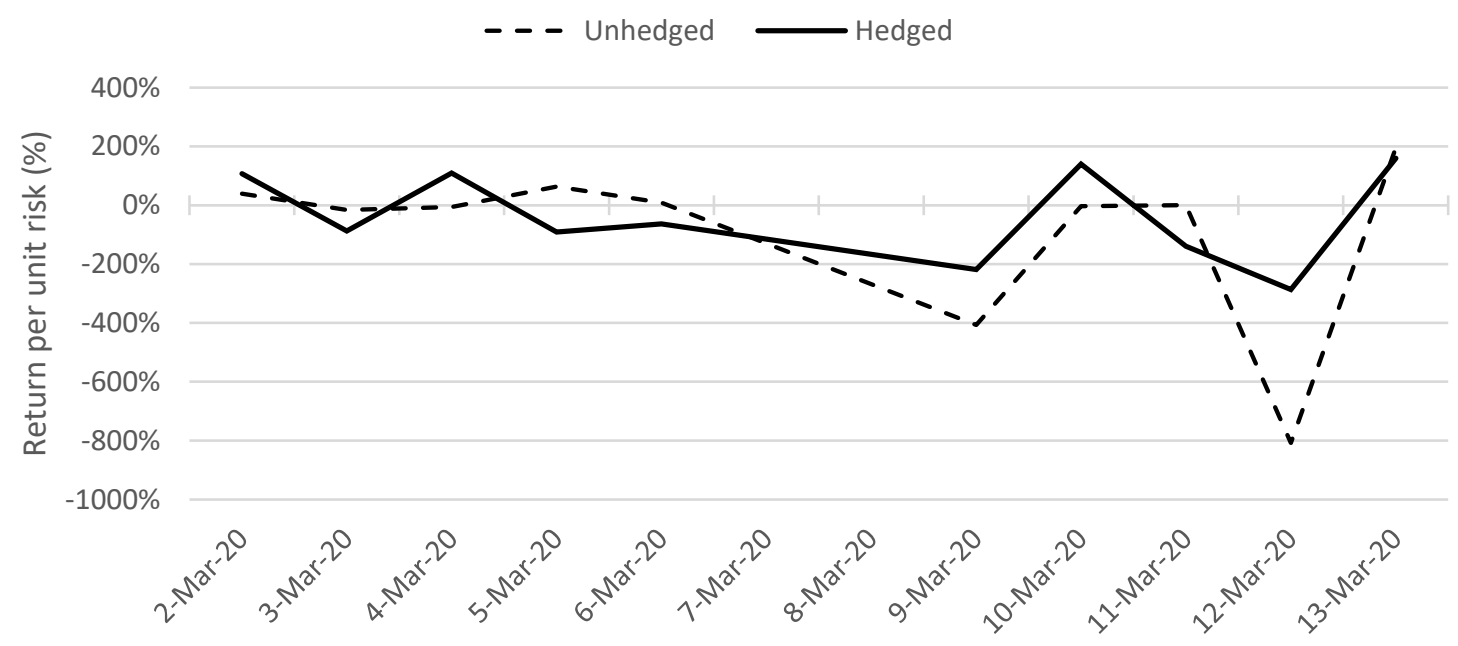

Figure 6. Return per unit risk (the NASDAQ with Bitcoin)

Notes: This figure shows the return per unit risk of the NASDAQ with Bitcoin before and after hedging to illustrate the performance of hedging by Bitcoin.

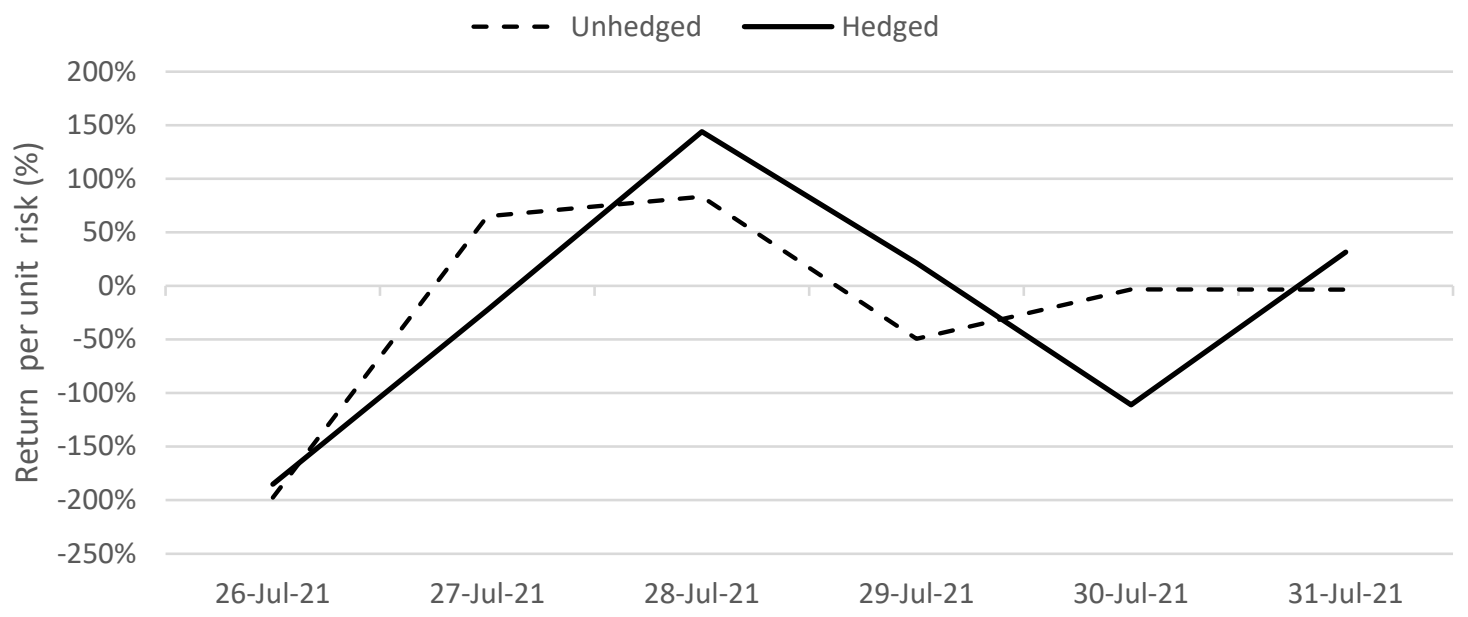

Figure 7. Return per unit risk (Education Portfolio with Bitcoin)

Notes: This figure shows the return per unit risk of the portfolio with Bitcoin before and after hedging to illustrate the performance of hedging by Bitcoin.

Table 2. Education portfolio composition

\begin{tabular}{ccc}
\hline Symbol & Company & Weight \\
\hline TAL & Tomorrow Advancing Life Education Group & 0.3822 \\
EDU & New Oriental Education \& Technology Group & 0.3457 \\
DAO & Youdao, Inc. & 0.1185 \\
GOTU & Gaotu Techedu, Inc. & 0.0801 \\
ZME & Zhangmen Education Inc. & 0.0717 \\
\hline
\end{tabular}

Notes: The education portfolio is constructed according to 2.2.3 to study whether Bitcoin can hedge the double-reduction policy on related stocks. 
Table 3. Hedging ratio (h) and hedging effectiveness (HE) of Short-Term hedging portfolios

\begin{tabular}{ccc}
\hline Hedge Portfolios & $\mathrm{h}$ & $\mathrm{HE}$ \\
\hline S\&P500 vs. BTC & 0.2571 & $56.68 \%$ \\
NASDAQ vs. BTC & 0.3026 & $63.84 \%$ \\
Education Portfolio vs. BTC & 3.6012 & $40.38 \%$ \\
\hline
\end{tabular}

Notes: This table reports the hedge ratio (h) of short-term hedged assets and Bitcoin hedging transactions and each sample period's hedging effectiveness (HE).

Figure 3 illustrates that although the hedging effect of the s\&p500 with Bitcoin is not that significant, the average return per unit risk after the hedging from March 3, 2020, to March 13, 2020, is bigger than before the hedging. And, the hedging effectiveness (HE) is shown in Table 2, the Bitcoin can hedge $56.68 \%$ of the risk of the S\&P 500, which can eliminate more than half of the risk. In Figure 4, the effect of hedging the NASDAQ with Bitcoin from March 3, 2020, to March 13, 2020, is more obvious that the fluctuation after hedging is more stable than before, and the average return per unit risk after hedging is also higher than before hedging. From Table 2, the hedge effectiveness (HE) of this hedge portfolio is $63.84 \%$. According to Figure 5, we can see that the return per unit risk of the education stock portfolio is affected by the double reduction policy. On July 28, 2021, the return per unit risk was $143.96 \%$ which was the highest. By calculation, we also get that the hedge effectiveness (HE) is $40.38 \%$ from Table 2.

Therefore, in the short term, Bitcoin still acts as a hedge. Although the return per unit risk does not have that big difference before and after the hedge, the steady fluctuation after the hedge means the Bitcoin really can make us get more return after the hedge. The hedge effectiveness (HE) also shows it can eliminate almost half of the risk in the stock market during a short period. This result represents that Bitcoin has the main function in hedging the risk of market fluctuation in the short term

\section{CONCLUSION}

We adopted hedge portfolio return, return per unit risk, and hedge effectiveness as key metrics to test the hedging performance of Bitcoin both in the long term and short term. For the long-term effect of the pandemic, we obtained the following results: the average return per unit risk does not change a lot after the hedge, but Bitcoin can hedge about $9 \%$ of the risk of the stock. For the short-term effect, we find that the average return per unit risk is higher after the hedge, and Bitcoin can hedge almost half of the risk in the short term. Bitcoin has a hedging effect in both the long-term and short-term, but the short-term hedging effectiveness is much bigger than long-term, which means Bitcoin may be more useful to hedge the stock market in the short-term.

Our research leaves at least one question to be explored: Why is Bitcoin's short-term hedge against U.S. equity more effective than its long-term hedge? We suspect that this has a lot to do with the volatility of U.S. equity. As the sample time increases, the impact of special events on the volatility of U.S. stocks may diminish. We will study this in the future.

\section{REFERENCES}

[1] Haq, M. N., Impact of Covid 19 on thegloba 1 economy, COVID-19 Pandemic, Update 202 0, pp. 208-213. Available at: https://link.sprin ger.com/chapter/10.1007/978-981-15-7782-6_3.

[2] Acikgoz, A. G., The early impact of the Cov id-19 pandemic on the global and Turkish ec onomy, Turkish Journal of Medical Sciences, 2020,vol. 50, pp.520-526. DOI: https://doi.org /10.3906/sag-2004-6.

[3] Yousfi, M., Effects of the COVID-19 pandem icon the US stock market and uncertainty, Te chnological Forecasting and Social Change, 2 021, vol. 161, forthcoming. DOI: https://doi.or $\mathrm{g} / 10.1016 / \mathrm{j}$.techfore.2021.120710

[4] Hong, H., COVID-19 and instability of stock market performance: evidence from the U.S, Financial Innovation, 2021, vol. 7, forthcomin g. DOI:https://doi.org/10.1186/s40854-021-0022 9-1

[5] Desk, Explained: reason behind bitcoin's mete oric rise in 2020, India Today, 2020. Availab le at:https://www.indiatoday.in/business/story/ex plained-reason-behind-bitcoin-s-meteoric-rise-in2020-1753735-2020-12-28.

[6] Shu, M., The "Covid" crash of the 2020 U.S. stock market, The North American Journal o f Economics and Finance, 2021, vol. 58, pp. 101497. DOI: https://doi.org/10.1016/j.najef.20 21.101497

[7] Choi, H., Investor attention and bitcoin liquid ity:evidence from bitcoin tweets, Finance Res 
earch Letters, 2021, vol. 39, pp. 101555. DO I: https://doi.org/10.1016/j.frl.2020.101555

[8] Sebastião, H., Pedro, G., Bitcoin futures: an effective tool for hedging cryptocurrencies. Fi nanceResearch Letters, 2020, vol.33, pp. 1012 30. DOI: https://doi.org/10.1016/j.frl.2019.07.0 03

[9] Stensås, A., Can bitcoin be a diversifier, hed geor safe haven tool, Cogent Economics Fina nce, 2019, vol. 7, pp. 1593072. DOI: https:// doi.org/10.1080/23322039.2019.1593072

[10] Mokni, K., Does bitcoin hedge categorical ec onomic uncertainty, A quantile analysis, SAG E Open, 2021 vol. 11, pp. 215824402110163. DOI:https://doi.org/10.1177/215824402110163 77

[11] Wang, G.J, Is bitcoin a haven or a hedge ass et?Evidence from China, Journal of Managem ent Science and Engineering, 2019, vol. 4, pp. 173-188. DOI: https://doi.org/10.1016/j.jmse.2 019.09.001

[12] Robert, F., Can cryptocurrency hedge against a stock market crash, The College Investor, 3 1 Oct, 2020. Available at: https://www.thecoll egeinvestor.com/34659/cryptocurrency-hedge/.

[13] Sen, W.K, The impact of oil price shocks on the stock market return and volatility relation ship,Electronic Journal, 2015, vol. 34, pp. 4154. DOI: http://dx.doi.org/10.1016/j.intfin.2014. 11.002

[14] Banton, C., An introduction to U.S. stock ma rket indexes, Investopedia, 18 Aug, 2021. Av ailable at: https://www.investopedia.com/insight s/introduction-to-stock-market-indices/.

[15] Kariya.T, Liu.R.Y, Options, futures and other derivatives, Asset Pricing, 2003, pp. 9-26. DOI:http://dx.doi.org/10.1007/978-1-4419-92307_2

[16] Louis, H. E., The hedging performance of th e new futures markets,1979, vol. 34, pp.157-1 70. DOI: https://doi.org/10.2307/2327150 